\title{
Relation between apnoea duration and type and neurological status of preterm infants
}

\author{
M C BUTCHER-PUECH, D J HENDERSON-SMART, D HOLLEY, J L LACEY, \\ AND D A EDWARDS
}

Departments of Perinatal Medicine and Physiotherapy, Royal Prince Alfred Hospital, Sydney, Australia

SUMMARY The incidence, duration, and type of apnoea were determined in 28 preterm infants born at 27 to 34 weeks' gestation, using polygraphic records of abdominal breathing movements and nasal airflow. Of the 1520 episodes of apnoea of 10 or more seconds duration, $1002(66 \%)$ lasted 10 to 14 seconds, $311(20 \%)$ lasted 15 to 20 seconds, and $207(14 \%)$ lasted more than 20 seconds. Overall, $69 \%$ were central in type, $20 \%$ were mixed, and $11 \%$ were purely obstructive. With increasing duration of apnoea, the proportion of episodes of central apnoea decreased (69 to $29 \%$ ) while that of mixed apnoea increased (20 to $60 \%$ ). Eight infants had obstructive apnoea of more than 20 seconds duration. When they were compared with the 10 infants of similar gestational age and birthweight who had central or mixed apnoea, they had a higher incidence of intraventricular haemorrhage, hydrocephalus, positive pressure ventilation via an endotracheal tube, and abnormal neurological development during the first year of life.

Prolonged apnoea, with or without bradycardia and cyanosis, occurs relatively frequently in preterm infants. Clinical studies have established that the incidence of recurrent episodes, as detected by clinical monitors, increases with decreasing weight ${ }^{1}$ and gestational age at delivery, ${ }^{2}$ and this has been related to neural immaturity of the brainstem. ${ }^{3}$ In some infants, the severity of apnoea has been related to various clinical disturbances such as infection, hypoglycaemia, and hypoxaemia. ${ }^{4}$ The precise pathophysiological nature of each apnoeic event, however, is still under investigation.

For some time it has been thought that these events are due to an intermittent cessation of respiratory efforts (central apnoea) and that they may represent an extension of the commonly observed periodic pattern, with its frequent brief pauses in breathing. ${ }^{15}$ As recently reviewed by Thach, ${ }^{6}$ simultaneous measurements of both air flow and breathing efforts have shown that some episodes are due to transient upper airway obstruction. Opinions differ, however, as to whether obstructive or central apnoea is the most common type observed.

To explore this further, we studied the interrelation between apnoea duration, apnoea type, and neurological status of preterm infants.

\section{Methods}

Polygraphic recordings on 28 infants born at less than 35 weeks' gestation were performed between January 1982 and October 1983. This was a selected group of infants, since clinically apnoeic infants, particularly those who seemed to have obstructive apnoea, were chosen for study. Gestational age was assessed from maternal menstrual history or an ultrasound scan before 20 weeks' gestation. If neither of these was available, a Dubowitz assessment was performed. ${ }^{7}$ The mean gestational age was 29.5 weeks (range 27 to 34 weeks) and the mean (SD) birthweight was $1.27(0.35) \mathrm{kg}$. The sex ratio was 1.

Recordings were made on a 4 channel Grass polygraph at postmenstrual ages of between 28 and 44 completed weeks. Fifteen of the 28 infants underwent longitudinal studies beginning within the first 10 days of life (or within the first 10 days after extubation) and then every two to four weeks while they continued to have episodes of apnoea. Sixty three recordings with a total duration of $242 \cdot 8$ hours were analysed. The mean total duration of recordings analysed for each infant was 8.6 hours (range of 2.8 to 20.5 hours). The mean duration of each individual recording was 3.9 hours (range of 1.5 to 8 hours). 
Studies were carried out in the newborn nursery, in the infant's usual environment while all support therapy was maintained, including monitoring and thermal control. During the recording, the baby was lying on its side with a 5 FG orogastric feeding tube in situ. Some of the infants on whom longitudinal recordings were being made were in a cot without a gastric tube for the last study. Beat to beat heart rate was recorded from the electrocardiogram leads via a Grass-7P4F tachograph, abdominal breathing movements were measured with a mercury in rubber strain gauge, and nasal airflow was detected using a thermistor in the upper nostril. The baby was continuously observed throughout the recording and these observations were marked on the polygraph.

Ten babies were being treated with theophylline at the time of some recordings, and 15 were being given oxygen treatment via a headbox. Since neither of these treatments seemed to alter the type of apnoea, the data for each infant were pooled.
Intraventricular haemorrhage occurred in seven babies, and was diagnosed either on clinical grounds in three (association of general collapse, abnormal neurological signs, and a rapid fall in haemoglobin) or by head ultrasound using a sector scanner in the remaining four.

Within 24 hours of the polygraphic recordings, a brainstem auditory evoked response was elicited by an Amplaid Mk4/8 system signal processor. The method has been described in detail elsewhere. ${ }^{3}$ The response was graded as either abnormal or transiently abnormal, or normal, based on wave form and threshold measurements. In 26 infants, neuromuscular development was assessed longitudinally during the preterm period, by a physiotherapist (JL) who was unaware of the results of the polygraphic study. The neurological assessment method was one adapted for preterm infants from that of Prechtl. ${ }^{8}$ At follow up, motor development was evaluated by both a paediatrician and a physiotherapist.

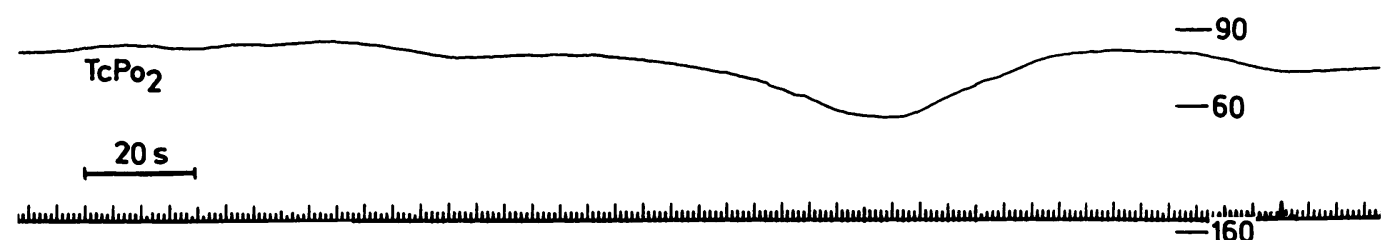

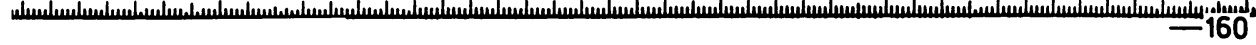
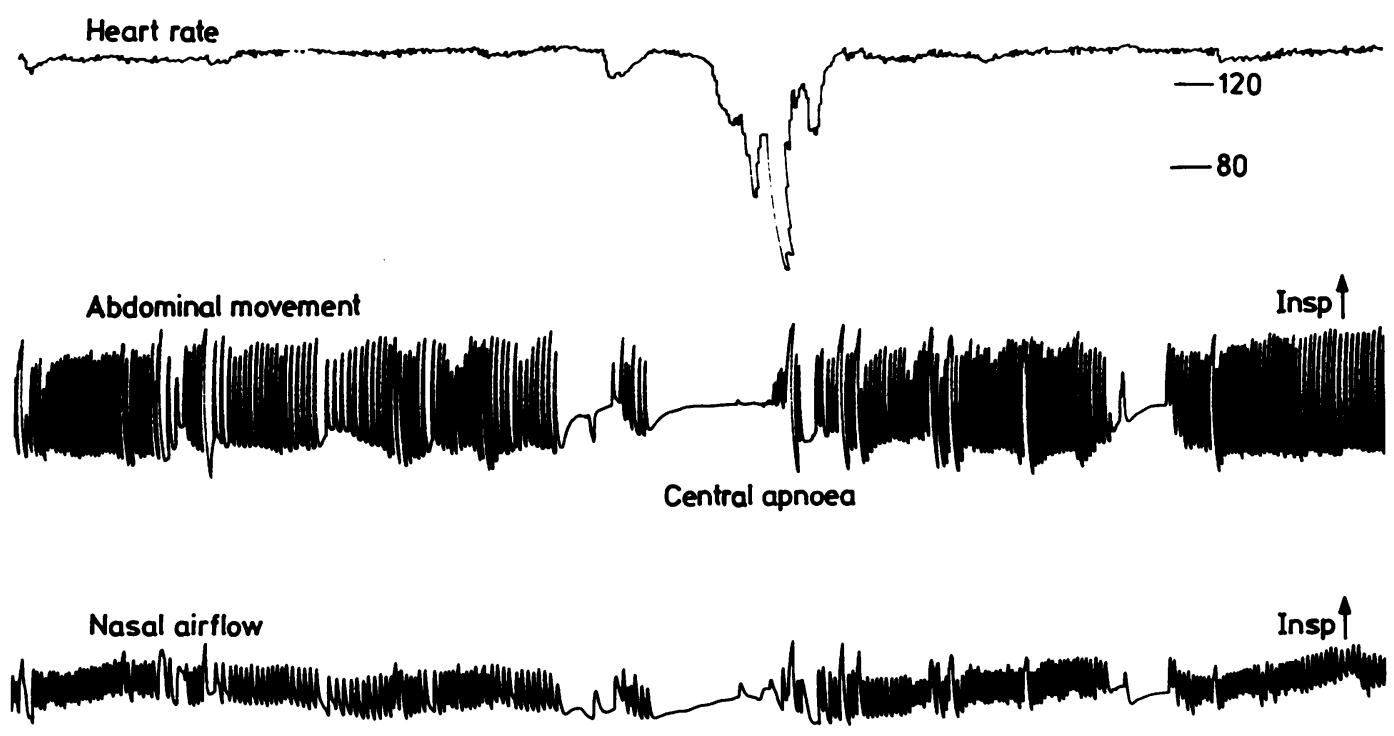

Fig. 1 Recordings of transcutaneous oxygen tension $\left(\mathrm{TcPo}_{2}\right)(\mathrm{mmHg}, 60=8 \mathrm{kPa}, 90=12 \mathrm{kPa})$, heart rate (beats per min), abdominal breathing movements (reflecting diaphragm descent) and nasal airflow. A central apnoea is indicated by simultaneous cessation of breathing efforts and airflow. At the end of the episode of apnoea, resumption of breathing efforts is accompanied by nasal airflow and an immediate recovery from bradycardia. 


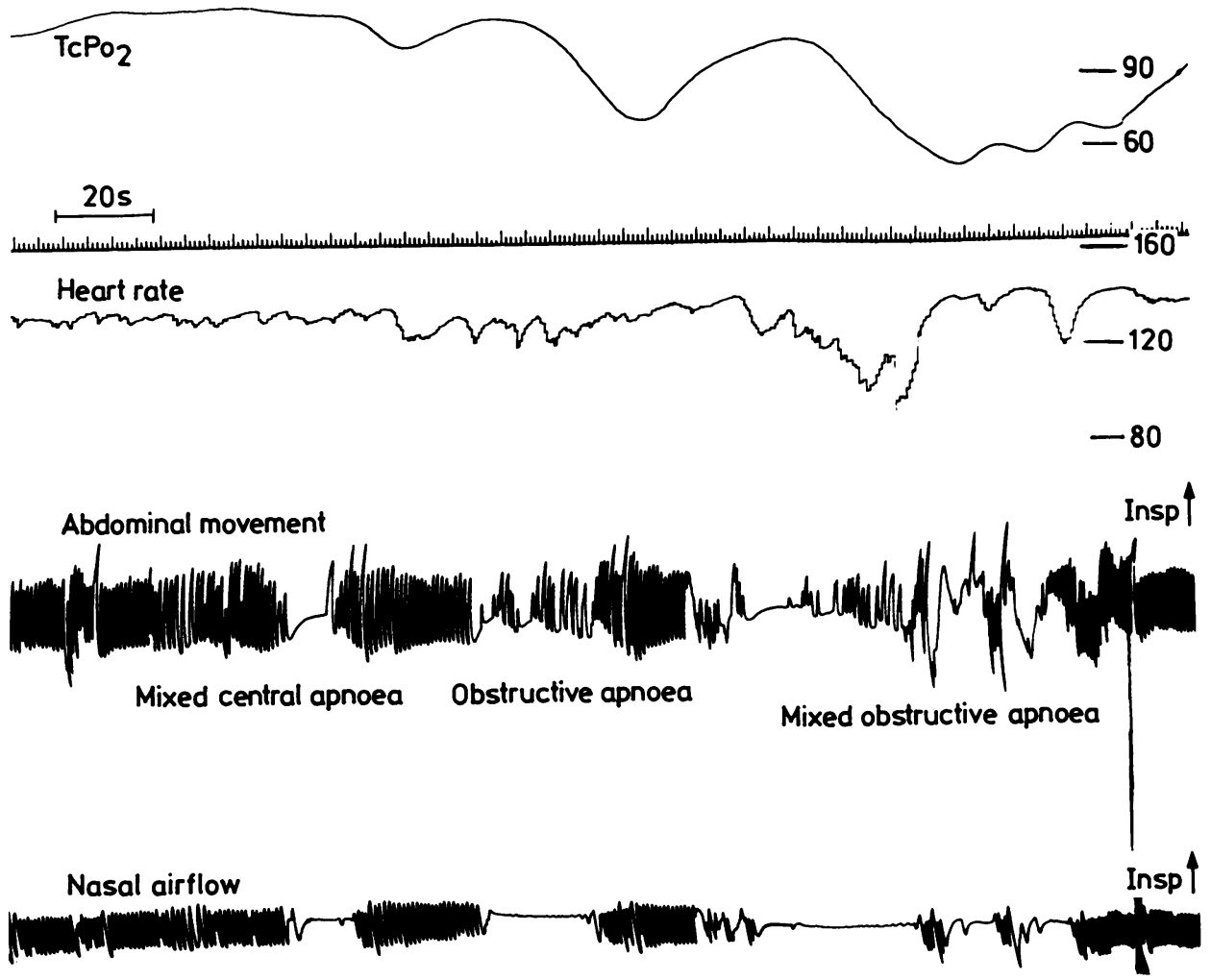

Fig. 2 Recorded variables as in Fig. 1, showing three episodes of apnoea with variable amounts of obstruction. The first apnoea (mixed central) begins with a simultaneous cessation of breathing efforts and airflow and ends after a series of rhythmic efforts without airflow (obstruction). The mixed obstructive apnoea begins and ends in a similar fashion except that the predominant component is obstructive. In the obstructive apnoea, efforts continue throughout while nasal airflow ceases. This recording is typical of the infants classified as having predominantly obstructive apnoea (Table I).

Apnoea was defined as a cessation of nasal air flow of 10 seconds or more. A distinction was made between three types of apnoea. Central apnoea was defined as a cessation of both breathing movements and nasal airflow (Fig. 1). The end of the apnoea was defined as the resumption of two or more breaths on the nasal flow trace within three seconds. Obstructive apnoea was defined by a cessation of nasal flow with continued breathing movements (Fig. 2). Apnoea was classified as mixed if there was a combination of central apnoea with at least three obstructed breaths (Fig. 2). The episodes of mixed apnoea were divided into two types, mixedobstructive if predominantly obstructive and mixedcentral if predominantly central. Episodes of generalised body movements which were accompanied by appreciably diminished airflow, uncoordinated breathing movements, and acceleration of the heart rate were excluded from analysis (Fig. 3).
Statistical comparisons of means were carried out using the 2 sample Student's $t$ test, and proportions were evaluated with the Fisher's exact test for small numbers and with the $\mathrm{Z}$ test or $\chi^{2}$ test for larger numbers.

\section{Results}

A total of 1520 episodes of apnoea with a duration of 10 or more seconds were recorded. The duration of apnoea was 10 to 14 seconds in $1002(66 \%), 15$ to 20 seconds in $311(20 \%)$, and more than 20 seconds in $207(14 \%)$. Overall, 1055 episodes $(69 \%)$ were of central apnoea, $205(13 \%)$ were mixed-central apnoea, $100(7 \%)$ were mixed-obstructive apnoea, and $160(11 \%)$ were purely obstructive in type. Both overall, and at each duration, episodes of central and mixed apnoea were more common than purely obstructive ones $(\mathrm{P}<0.001$ in each case $)$. In each 

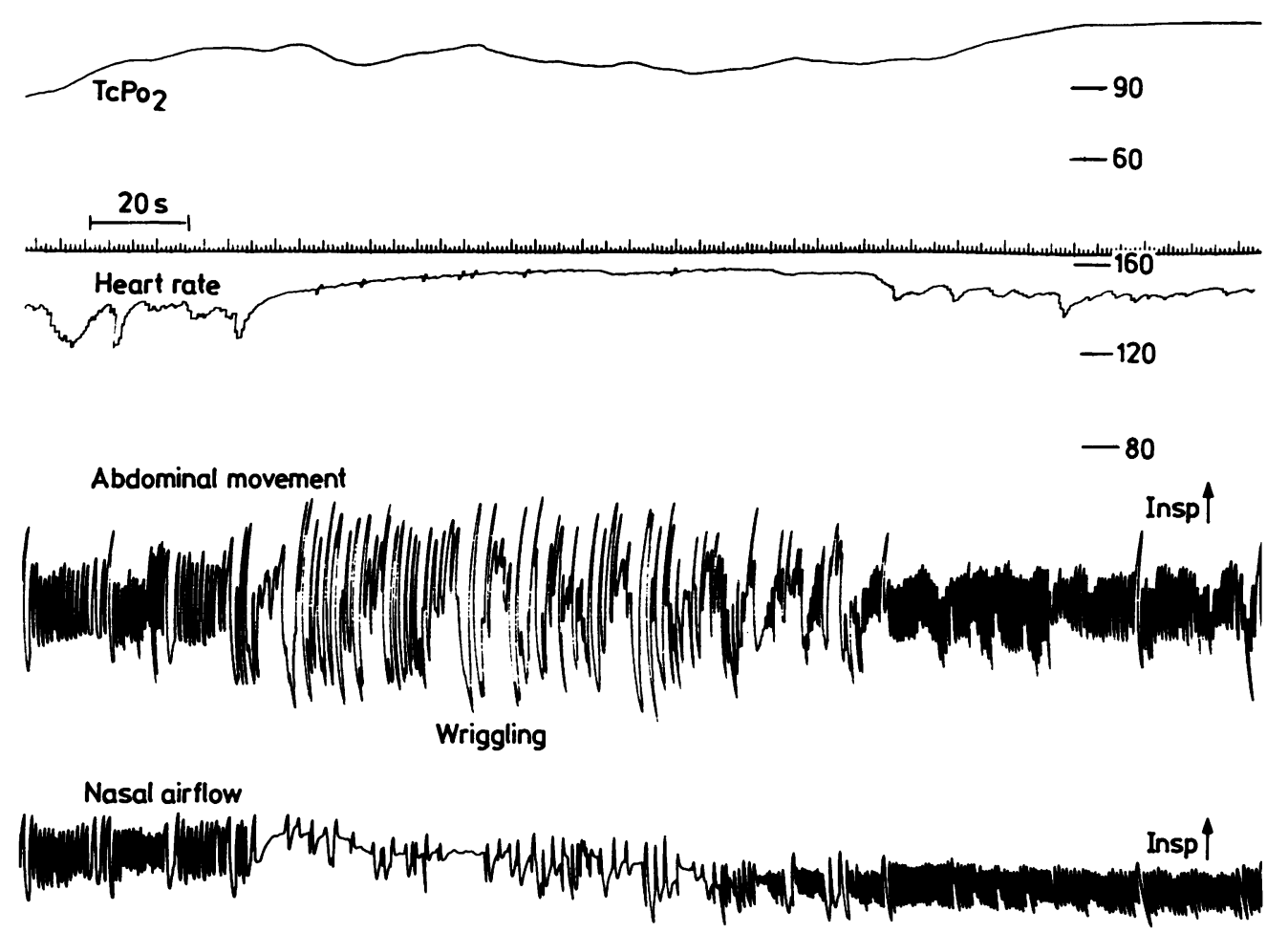

Fig. 3 Recorded variables as in Fig. 1, showing an episode of wriggling in which generalised body movements are accompanied by disorganised breathing efforts, diminished nasal airflow and an acceleration of heart rate. These episodes were excluded from analysis in the present study.

episode of mixed apnoea, the obstructive component followed an initial cessation of breathing efforts. No episode of central or mixed apnoea seemed to begin with obstruction.
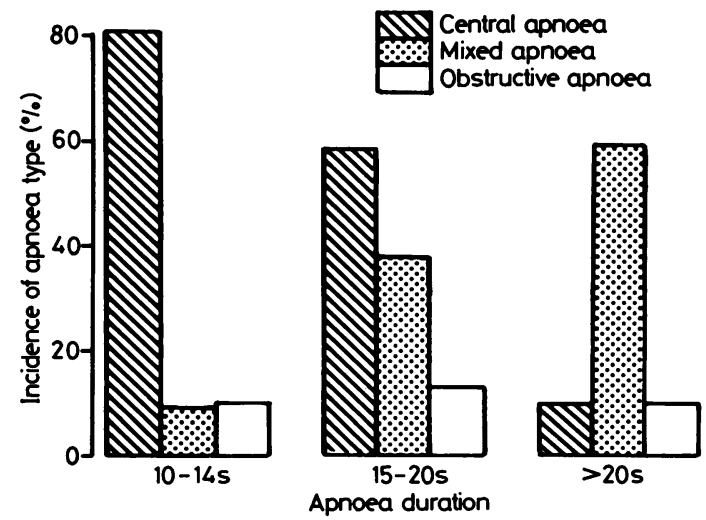

Fig. 4 The incidence of apnoea of different types at each apnoea duration.
As shown in Fig. 4, central apnoea predominated $(81 \%)$ in the 10 to 14 seconds group. There was a highly significant decrease in the proportion of central apnoea with increasing apnoea duration $(\mathrm{P}<0.001)$. Conversely, mixed apnoea predominated $(60 \%)$ in episodes of greater than 20 seconds duration, and there was a highly significant increase in the proportion of these episodes with increasing apnoea duration $(\mathrm{P}<0.001)$. The proportion of obstructive apnoea remained about $10 \%$ for each apnoea duration.

When babies were grouped according to type of apnoea in episodes lasting more than 20 seconds (Table), 10 had not suffered such a lengthy episode during the recordings, 10 had central or mixed apnoea, and eight had an obstructive pattern (at least one purely obstructive episode greater than 20 seconds). The first group were of greater gestation and birthweight, and therefore were not comparable with the other two groups. Statistical comparisons between the 'obstructive' group and the 'central and mixed' group, showed that there was no significant difference in gestation or weight at birth, theophyl- 
Table Comparison of infants grouped according to type of apnoea during episodes lasting more than 20 seconds

\begin{tabular}{|c|c|c|c|c|}
\hline & $\begin{array}{l}\text { (a) Obstructive } \\
(n=8)\end{array}$ & $\begin{array}{l}\text { (b) Central and mixed } \\
(n=10)\end{array}$ & $\begin{array}{l}\text { (c) Non-apnoeic } \\
(n=10)\end{array}$ & $\begin{array}{l}P \text { values } \\
\text { (a) } v(b)\end{array}$ \\
\hline $\begin{array}{l}\text { Gestational age } \\
\text { Mean (SD) }\end{array}$ & $28.5(2.1)$ & $28.6(2.4)$ & $31.1(1.9)$ & ns \\
\hline Birthweight (kg) & & $20.0(2.4)$ & $3 x \cdot 1(1.9)$ & His \\
\hline Mean (SD) & $1 \cdot 16(0.2)$ & $1.26(0.4)$ & $1.37(0.39)$ & ns \\
\hline IPPR $>3$ days & 7 & 1 & 2 & $<0.002$ \\
\hline IVH & 6 & 1 & 0 & $<0.01$ \\
\hline Hydrocephalus & 4 & 0 & 0 & $<0.05$ \\
\hline Abnormal BAERs* & 4 & $1 / 9$ & 1 & ns \\
\hline $\begin{array}{l}\text { Neonatal neurological* } \\
\text { abnormalities }\end{array}$ & 7 & $1 / 8$ & 2 & $<0.005$ \\
\hline $\begin{array}{l}\text { Neurological abnormalities } \\
\text { at follow up }>1 \text { year* }\end{array}$ & 5 & 1 & 1 & $<0.03$ \\
\hline
\end{tabular}

*See text for more details.

$\mathrm{ns}=$ not significant; $\mathrm{IPPR}=$ intermittent positive pressure respiration; IVH=intraventricular haemorrhage; $\mathrm{BAER}=$ brainstem auditory evoked response.

line or oxygen treatment at the time of the study, or the incidence of oxygen dependency (more than 30 days). Babies with obstructive apnoea of more than 20 seconds in duration, however, had a higher incidence of intermittent positive pressure ventilation via an endotracheal tube for more than three days, intraventricular haemorrhage, hydrocephalus, unusual features of neuromuscular development during the preterm period, and major neurological abnormalities at age 1 year. These preterm features included one or more of the following after 37 weeks' postmenstrual age: movement dominated by (a) asymmetrical tonic neck reflex (5 of 7) or (b) slow beat wide amplitude jitters (5 of 7), or both; plus low tone resulting in (a) failure to develop any degree of lower limb antigravity posturing (5 of 7) or (b) head lag $>40^{\circ}$ when tested supine to sitting ( 5 of 7). Abnormal development at 1 year included spastic cerebral palsy (3), deafness with convulsions (1), microcephaly but motor development normal (1), and extreme developmental delay (1). Although more infants with obstructive apnoea had abnormal brainstem evoked responses, the numbers are small and the differences do not reach statistical significance.

\section{Discussion}

In this study episodes of apnoea were predominantly central or mixed rather than purely obstructive in type. This finding is similar to the results of Lopes et $a l^{9}$ and Dransfield $e t$ al, ${ }^{10}$ although the latter authors emphasised the obstructive components during mixed apnoea. Thach has placed more emphasis on obstructive apnoea. ${ }^{6}$ To explain the obstruction, Milner and colleagues ${ }^{11}$ drew attention to airway closure during the initial central component in $50 \%$ of episodes of apnoea in preterm infants. This was detected by a disappearance of the cardiac artifact on the flow trace and was more likely to be followed by obstruction when breathing efforts resumed (mixed apnoea).

Differences between the results of various studies can be largely explained by differences in patient selection, in methodology, and in the definition of apnoea. Studies have usually been on selected infants who had clinical apnoea ${ }^{6-11}$ or in one instance, infants who had no apparent apnoea. ${ }^{12}$ The definition of apnoea has varied from all pauses in breathing of more than two seconds ${ }^{12}$ or more than five seconds ${ }^{11}$ to episodes of more than 20 seconds together with shorter events if they were associated with bradycardia. ${ }^{6910}$ In most studies, episodes associated with generalised body movements, during which airway closure and even vocalisation may occur, have not been excluded. It has been suggested ${ }^{13}$ that inclusion of these episodes causes excessive emphasis on obstructive apnoea. These episodes were excluded from the present analysis.

Examination of the type of apnoea at each duration showed a changing pattern not previously reported. Episodes of central apnoea predominate at the shorter durations while mixed apnoea is more common in the longer episodes. This could explain the emphasis on mixed apnoea given by those studying only longer events. ${ }^{6}{ }^{10}$ There are several possible explanations for the increasing incidence of mixed apnoea at longer apnoea durations. The obstruction may simply lead to prolongation of the apnoea; ${ }^{11}$ however, this does not explain why the obstructive breaths occur. An alternative explanation could be that the response to the rapidly developing chemoreceptor drive during the initial central component may actually lead to the obstruction. With the increasing duration of apnoea, the chemoreceptor drive to the respiratory muscles would be greater. There is some evidence that there 
is a differential effect of this stimulus, with diaphragmatic activity being enhanced before that of the upper airway muscles. ${ }^{14} 15$ This could explain the occurrence of a few obstructed breaths at the end of pause in breathing, leading to mixed apnoea.

The enhanced chemoreceptor drive in prolonged apnoea may even cause inhibition. Since hypoxaemia develops rapidly during apnoea in preterm infants, ${ }^{16}$ this may cause reflex motor neurone inhibition, as observed in the fetus, ${ }^{17}$ and lead to a reduction of upper airway muscle tone. Airway closure during central apnoea, as observed by Milner, ${ }^{11}$ would be favoured by hypotonia, which would lead to the need for increased upper airway dilator activity to overcome the surface forces causing adherence of the tongue and pharyngeal walls. Such a mechanism has been shown in a necropsy study of infants. ${ }^{6}$ In that study and in observations of preterm infants, ${ }^{6}$ the influence of posture on upper airway obstruction has been emphasised. An important component in this mechanism may be the quantity and quality of secretions present in the upper airway. After prolonged intubation these secretions may be altered and this could explain the association between intubation and obstructive apnoea (Table 1). Alternatively, endotracheal intubation could physically damage upper airway mucosal receptors that respond to pressure. It has been suggested that these play a role in the reflex control of upper airway muscles $^{18}$ and may be important in the responses to airway obstruction.

In the present study episodes of purely obstructive apnoea were the least common at each duration. As a group, infants with obstructive apnoea of more than 20 seconds duration had evidence of neurological abnormality (Table). The present observation of an association with intracranial haemorrhage has also been noted by Lopes et al. ${ }^{9}$ A neurological insult could lead to disordered upper airway control due to either direct depression of respiratory neurones or, more likely, a diffuse damage to neurones responsible for motor excitability. The latter is more likely since these infants have other evidence of widespread neuronal dysfunction both in the neonatal period and at follow up.

The authors thank the following people for their encouragement or assistance: Dr Bruce Storey, Dr Alan Pettigrew, Ruth Perrott, Louise Alexander, and Gwen Cox. The project was supported by grants from The National Health and Medical Research Council of
Australia, Ramaciotti Foundations, OPSM Foundation, and Postgraduate Medical Foundation of the University of Sydney.

\section{References}

1 Miller HC, Behrle FC, Smull NW. Severe apnea and irregular respiratory rhythms. Pediatrics 1959;23:676-85.

2 Henderson-Smart DJ. The effect of gestational age on the incidence and duration of recurrent apnoca in newborn babies. Aust Paediatr J 1981;17:273-6.

3 Henderson-Smart DJ, Pettigrew AG, Campbell DJ. Clinical apnoea and brain stem neural function in preterm infants. N Engl J Med 1983;308:353-7.

4 Kattwinkel J. Neonatal apnea; pathogenesis and therapy. J Pediatr 1977;90:343-7.

${ }^{5}$ Rigatto H, Brady JP. Periodic breathing and apnea in preterm infants. II. Hypoxia as a primary event. Pediatrics 1972;50: 219-28.

${ }^{6}$ Thach BT. The role of pharyngeal airway obstruction in prolonging infantile apneic spells. In: Tilden JT, Roeder LM, Steinschneider A, eds. Sudden infant death syndrome. New York: Academic Press, 1983:279-92.

7 Dubowitz LMS, Dubowitz V, Goldberg C. Clinical assessment of gestational age in the newborn infant. J Pediatr 1970;77:1-10.

${ }^{8}$ Prechtl HFR. The neurological examination of the full-term newborn infant. Clinics in developmental medicine vol. 63 . London: Heineman, 1977.

${ }^{9}$ Lopes J, Muller N, Bryan MH, Lesouef P, Bryan AC. Central and obstructive apneas in preterm infants. Clin Invest Med 1981;4(Suppl):44B

10 Dransfield DA, Spitzer AR, Fox WW. Episodic airway obstruction in premature infants. Am J Dis Child 1983;137:441-3.

$"$ Milner AD, Boon AW, Saunders RA, Hopkin IE. Upper airways obstruction and apnoea in preterm babies. Arch Dis Child 1980;55:22-5.

12 Curzi-Dascalova L, Christova-Gueorguleva E. Respiratory pauses in normal prematurely born infants. Biol Neonate 1983;44:325-32.

13 Someren V Van, Stothers JK. A critical dissection of obstructive apnea in the human infant. Pediatrics 1983;71:721-5.

14 Patrick GB, Strohl KP, Rubin SB, Actose MD. Upper airway and diaphragm muscle responses to chemical stimulation and loading. J Appl Physiol 1982;53:1133-7.

15 Carlo WA, Martin RJ, Abboud EF, Bruce EN, Strohl KP. Effect of sleep state and hypercapnia on alae nasi and diaphragm EMGs in preterm infants. $J$ Appl Physiol 1983;54:1590-6.

16 Henderson-Smart DJ. Vulnerability to hypoxaemia during sleep in the newborn. Sleep 1980;1:195-208.

17 Blanco CE, Dawes GS, Walker DW. Effect of hypoxia on poly-synaptic hind limb reflexes on unanaesthetised fetal and newborn lambs. J Physiol 1983;339:453-66.

18 Mathew OP, Remmers JE. Respiratory function of the upper airway. In: Saunders NA, Sullivan CE, eds. Sleep and breathing. New York: Marcel Decker, 1984.

Correspondence to Dr D J Henderson-Smart, Perinatal Medicine, Royal Prince Alfred Hospital, Camperdown, Sydney, NSW 2050, Australia.

Received 21 May 1985 